\title{
Inertial sensors in the motor assessment of Parkinson's Disease in patients who underwent Pallidotomy
}

\author{
Sensores inerciais na avaliação motora da Doença de Parkinson em pacientes submetidos à \\ Palidotomia
}

Sensores inerciales en la evaluación motora de la Enfermedad de Parkinson en pacientes sometidos

a palidotomía

Received: 11/04/2021 | Reviewed: 11/11/2021 | Accept: 11/19/2021| Published: 11/28/2021

\author{
Gabriel Pereira Escudeiro \\ ORCID: https://orcid.org/0000-0002-3330-5463 \\ Universidade Federal Fluminense, Brazil \\ E-mail: gabrielescudeiro@yahoo.com.br \\ Adriano de Oliveira Andrade \\ ORCID: https://orcid.org/0000-0002-5689-6606 \\ Universidade Federal de Uberlândia, Brazil \\ E-mail: aoandrade.ufu@ gmail.com \\ Ariana Moura Cabral \\ ORCID: https://orcid.org/0000-0002-9804-353X \\ Universidade Federal de Uberlândia, Brazil \\ E-mail: arianacabral57@gmail.com \\ Marco Antonio Araujo Leite \\ ORCID: https://orcid.org/0000-0003-1447-3696 \\ Universidade Federal Fluminense, Brazil \\ E-mail: maaraujoleite@yahoo.com.br \\ Leonardo Vasques Monteiro \\ ORCID: https://orcid.org/0000-0001-5265-0601 \\ Universidade Federal Fluminense, Brazil \\ E-mail: leonardovasques@id.uff.br \\ Igor Duque Gonçalves da Silva \\ ORCID: https://orcid.org/0000-0002-3542-8379 \\ Universidade Federal Fluminense, Brazil \\ E-mail: igor.duque@hotmail.com \\ Bruno Lima Pessôa \\ ORCID: https://orcid.org/0000-0002-9772-7649 \\ Universidade Federal Fluminense, Brazil \\ E-mail: brunopessoa@id.uff.br
}

\begin{abstract}
Parkinson's Disease is a neurodegenerative disorder with a great global impact and, despite recent advances, it still needs improvement in the methods for assessing motor alterations. This study aimed at evaluating a system (hardware and software) capable of accurately quantifying tremor in patients with Parkinson's disease that underwent pallidotomy. The Mean Absolute Value (MAV) of the involuntary activity of three patients that underwent pallidotomy surgery - in the pre and postoperative scenarios- was evaluated. The Mean Absolute Value of involuntary activity obtained through the suggested device (TREMSEN) showed a good correlation with the clinical findings, as well as with the findings already described in previous studies. The present study showed that MAV alterations were always positively related to tremor, or negatively related to bradykinesia and rigidity, or possibly both. A tendency towards greater tremor influence on the MAV than bradykinesia and rigidity was also observed. The positive correlation among the values measured by the TREMSEN device and the patients' clinical result opens doors for the future application of technology, such as accurate and objective assessment of motor disorders, continuous monitoring and remote monitoring.
\end{abstract}

Keywords: Parkinson Disease; Symptom assessment; Pallidotomy.

\section{Resumo}

A Doença de Parkinson é um distúrbio neurodegenerativo de grande impacto global, apesar dos avanços recentes ainda necessita de aprimoramento nos métodos de avaliação das alterações motoras. Este trabalho teve como objetivo avaliar um sistema (hardware e software) capaz de quantificar de forma precisa o tremor em pacientes com a doença 
de Parkinson submetidos à Palidotomia. Foi avaliado o Valor Absoluto Médio (MAV - Mean Absolute Value) da atividade involuntária de três pacientes submetidos à cirurgia de palidotomia nos cenários pré e pós-operatório. O Valor Absoluto Médio da atividade involuntária obtido por meio do dispositivo proposto (TREMSEN) apresentou boa correlação com os achados clínicos, bem como os achados já descritos em estudos anteriores. O presente estudo mostrou que as alterações da MAV estavam sempre relacionadas positivamente com tremor ou negativamente com bradicinesia e rigidez, ou eventualmente em ambos. Também se observou a tendência à maior influência do tremor sobre a MAV do que bradicinesia e rigidez. A correlação positiva entre os valores aferidos pelo dispositivo TREMSEN e o resultado clínico dos pacientes abre portas para aplicação futura da tecnologia, tais como avaliação precisa e objetiva dos distúrbios motores, monitoramento contínuo e monitoramento à distância.

Palavras-chave: Doença de Parkinson; Avaliação de sintomas; Palidotomia.

\section{Resumen}

La Enfermedad de Parkinson es un trastorno neurodegenerativo de gran impacto global, que a pesar de los avances recientes, aún necesita mejorar los métodos de evaluación de las alteraciones motoras. Este estudio tuvo como objetivo evaluar un sistema (hardware y software) capaz de cuantificar con precisión el temblor en pacientes con enfermedad de Parkinson sometidos a palidotomía. Se evaluó el Valor Absoluto Medio (MAV) de la actividad involuntaria de tres pacientes sometidos a cirugía de palidotomía en los escenarios pre y posoperatorio. El Valor Absoluto Medio de la actividad involuntaria obtenido a través del dispositivo propuesto (TREMSEN) mostró una buena correlación con los hallazgos clínicos, así como con los hallazgos ya descritos en estudios previos. El presente estudio demostró que las alteraciones de las MAV siempre se relacionaron positivamente con el temblor o negativamente con la bradicinesia y la rigidez, o posiblemente ambas. También se observó una tendencia hacia una mayor influencia del temblor en la MAV que la bradicinesia y la rigidez. La correlación positiva entre los valores medidos por el dispositivo TREMSEN y el resultado clínico de los pacientes abre las puertas para la aplicación futura de la tecnología, como la evaluación precisa y objetiva de los trastornos motores, la monitorización continua y la monitorización remota.

Palabras clave: Enfermedad de Parkinson; Evaluación de síntomas; Palidotomía.

\section{Introduction}

Parkinson's Disease (PD) is the fastest growing neurodegenerative disorder in the recent years in terms of prevalence, disability and number of deaths. (Ray Dorsey et al., 2018) Its prevalence is 1-2 individuals per 1000 at all ages and affects $1 \%$ of the population over 60 years, being the second most common neurodegenerative disease. (Tysnes \& Storstein, 2017) (Ascherio \& Schwarzschild, 2016; Elbaz et al., 2016)

The current gold standard used to assess PD symptoms is the use of scales and questionnaires based on observation and clinical tests, either to quantify the severity of the disease or to assess the therapeutic response. The most used scale is the Movement Disorders Society - Unified Parkinson's Disease Rating Scale (MDS-UPDRS), which is divided into four parts, the third one (MDS-UPDRS-III) being responsible for the motor assessment. (Goetz et al., 2008) (Monje et al., 2019)

Objective ways to measure PD signs are widely discussed and researched. (Yang et al., 2016) This research suggests the TREMSEN device evaluation for the objective assessment of the PD cardinal signs with national production and within the scope of the public service, using inertial sensors capable of measuring movement.

The use of objective tools for the DP assessment can help the medications dosage adjustment, build prognostic models for the treatment of the disease and support the indication, planning and surgery implementation.

This study aims at evaluating the motor signs of patients with Parkinson's Disease who underwent pallidotomy with the TREMSEN device, as well as the description of the results obtained and their comparison with the neurological exam using the MDS-UPDRS-III scale.Use the paragraph as a template (TNR font 10 - justified - space 1,5).

\section{Methodology}

We conduced a prospective observational diagnostic pilot study to compare the results obtained with the proposed method (TREMSEN) with the established gold standard method (MDS-UPDRS-III) for the assessment of motor disorders in Parkinson's Disease. For this purpose, we decided to select patients who were already undergoing a conventional surgical 
schedule. This study design was based on similar previous studies. (Arora et al., 2015; Mera et al., 2013; Rigas et al., 2012)

This study was approved by the Institutional Ethics Committee (legal opinion 4,540,114) of the Fluminense Federal University. All study participants received a detailed explanation about the research protocol, as well as the risks and benefits, and voluntarily signed the Informed Consent Form (ICF).

All PD patients that underwent surgical treatment with pallidotomy between May and December 2019 were included in the project. All patients were under regular neurology and neurosurgery follow-up services. The selection and performance of surgeries were carried out in a clinical routine context, since surgery is a protocol and is routinely performed in clinical practice. As criteria for selecting patients for surgical treatment, the ones already established by the neurosurgery and neurology team at HUAP/UFF were used, which follow the guidelines of the CAPSIT-PD protocol (Defer et al., 1999). Exclusion criteria were high surgical risk, refusal by the patient or family members, or loss to outpatient follow-up.

Parkinson's Disease diagnosis was established by a neurologist with experience in Movement Disorders and based on the clinical criteria of the UK Brain Bank. (Gibb \& Lees, 1988) Motor complications such as dyskinesias, dystonias, painful dystonias, in addition to bradykinesia, rigidity and refractory tremor to drug treatment were considered. The criterion of refractoriness or intolerance to medications was also defined by an experienced neurologist.

All patients received the MDS-UPDRS, Schwab and England, Hoehn and Yahr scales, Mini Mental State Examination (Mini-mental), Montreal Cognitive Assessment (MoCA), in addition to depression tests and neuropsychological assessment, in order to rule out cognitive deficits or alterations that contraindicated surgical treatment. The motor function assessment was aided by a camera, recording the exam. Quantitative assessment of motor symptoms occurred through the objective assessment system, TREMSEN, described below.

All patients underwent preoperative and postoperative computed tomography of the skull and preoperative magnetic resonance imaging (MRI) of the brain (MRI with the acquisition of axial volumetric images at T1, with thin sections from 1.5 to $2 \mathrm{~mm}$, passing through the AC-PC plan).

\subsection{Equipment}

The TREMSEN biomedical device (Figure 1a) was created in 2014 by the Núcleo de Inovação e Avaliação Tecnológica em Saúde (Center for Innovation and Technological Assessment in Health) (NIATS) with the purpose of characterizing human tremor. The equipment consists of two parts: (1) inertial movement sensors and electromyography sensors (EMG); and (2) a hardware set, composed of a microcontroller (Arduino Duo), responsible for capturing and processing inertial and EMG signals; and communication cables.

Figure 1: a) TREMSEN device; b) position during use.

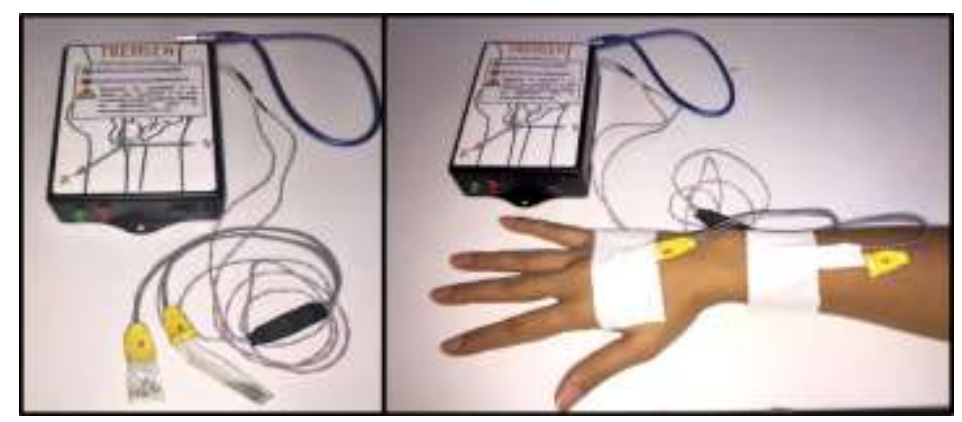

Source: Authors (2021). 
The inertial motion sensor used is comprised of a MinIMU (Inertial Measurement Unit) chip, which contains an accelerometer, a magnetometer and a triaxial gyroscope. They are able to provide positioning information in relation to the three Cartesian axes X, Y, Z.

The sensors are compact and energy efficient, mounted on a $20 \mathrm{~mm}$ x $13 \mathrm{~mm}$ x $3 \mathrm{~mm}$ board, with a $0.9 \mathrm{~g}$ mass, and wired to the microcontroller. Despite being designed for punctual clinical evaluation, their characteristics are favorable to be used incorporated into a wearable system, such as a glove, and for outpatient use.

The acquisition, visualization and storage of the signals are done by the TREMSEN software (Figure 2).

Figure 2: TREMSEN software during use.

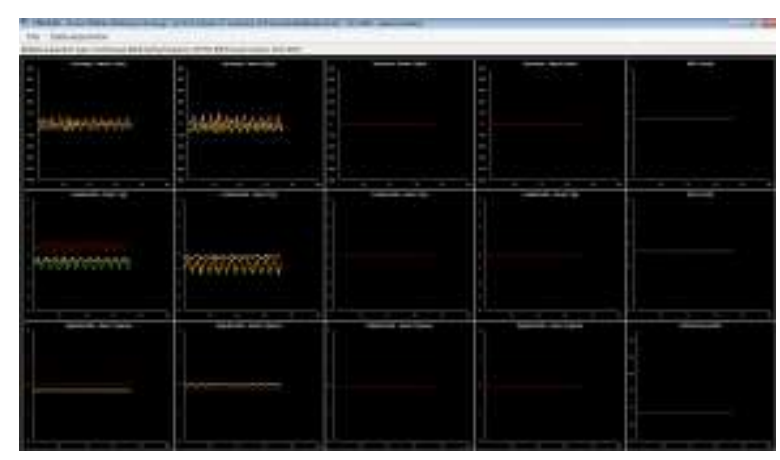

Source: Authors (2021).

\subsection{Objective evaluation by the TREMSEN Method}

The TREMSEN system has two sets of electrodes (electrodes 1 and 2), fixed in the same direction and direction; electrode 1 was positioned on the back of the hand, on the third metacarpal, $2 \mathrm{~cm}$ proximal to the metacarpal-phalangeal joint. Electrode 2 was positioned on the forearm, in the direction of sensor 1, 6-8 cm proximal to it (Figure 1b). These parameters were used in order to assess the wrist joint and hand movement, as they are two regions typically affected in Parkinson's Disease. (de Oliveira Andrade et al., 2020; Postuma et al., 2015)

The patients were evaluated in a chair with lateral support for the upper limbs, in which they were comfortably positioned to perform the tests, with their feet on the floor and their backs supported on the backrest, in an upright position. The forearms were supported on the lateral support in order to isolate the movement of the wrist and hands. Under TREMSEM registration, wrist flexion and extension movements, ulnar and radial deviation, and pronation and supination movements were performed, besides the research on resting and postural tremor, as shown in Figures 3-6.

Figure 3: Resting and postural analyses.

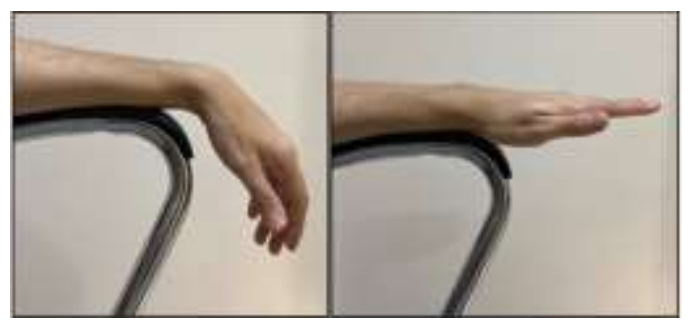

Source: Authors (2021)
Figure 4: Wrist flexion and extension.

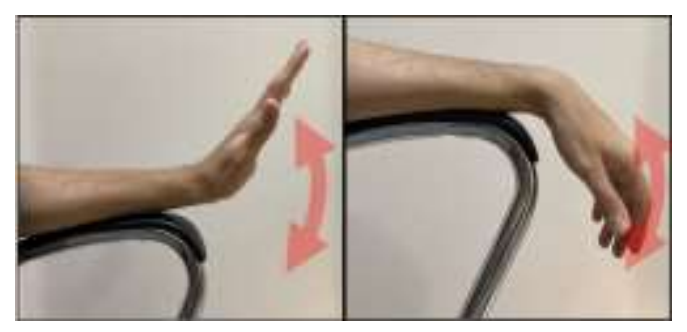

Source: Authors (2021) 
Figure 5: Pronation and supination.

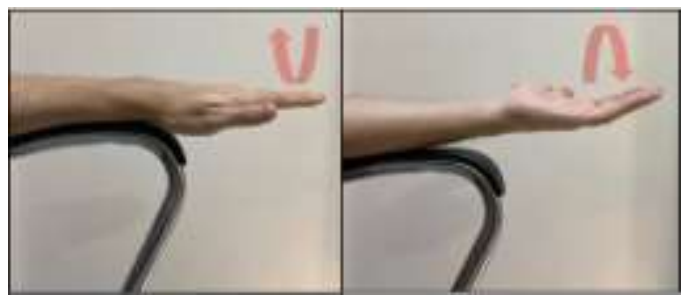

Source: Authors (2021)
Figure 6: Adduction and abduction.

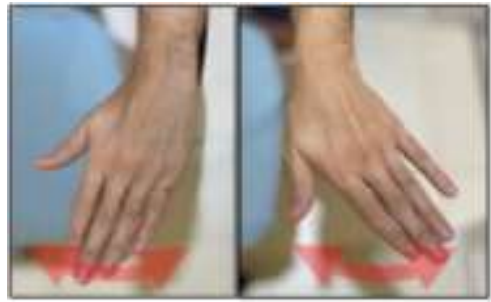

Source: Authors (2021)

This sequence of movements was performed being recorded with cameras, without identifying the patients' faces. Before recording with the equipment, this sequence of movements was demonstrated by the evaluator and performed by the patient for training purposes.

TREMSEN tests consisted of evaluating, first the most affected limb and then the least affected one. Soon after, the MDS-UPDRS-III evaluation was carried out and recorded by videotaping for further evaluation.

Patients who had at least one preoperative and one postoperative evaluation, at least 3 months after surgery, in the ON and OFF periods were included in the analysis (see Figure 7).

Figure 7: Patient's flowchart of inclusion in the study.

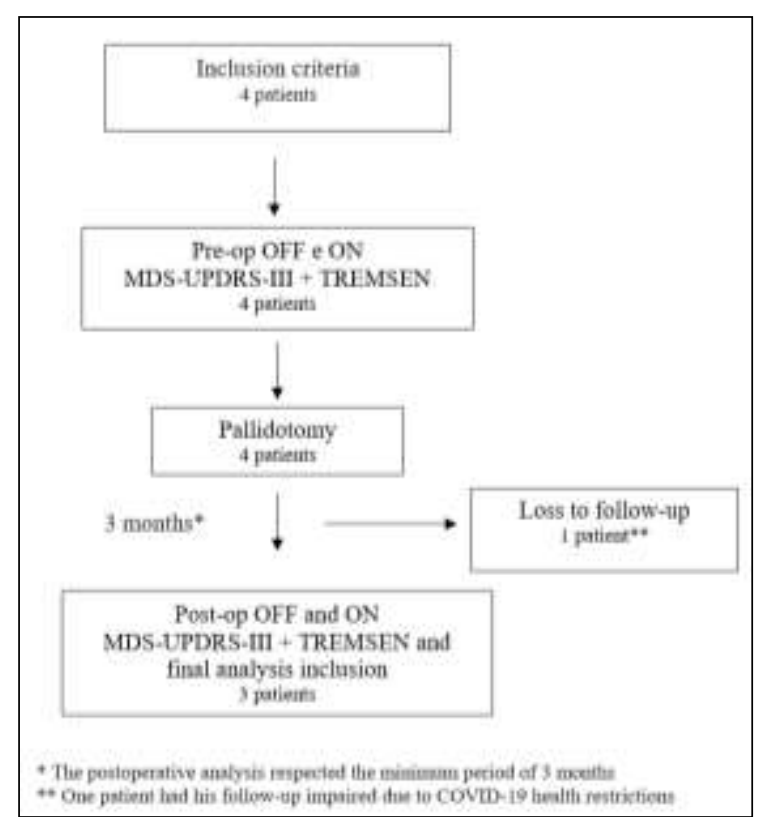

Source: Authors (2021)

\subsection{Data processing and statistical analysis}

The entire signal processing and statistical analysis was carried out in the R development environment.

The following steps were used in the data processing:

- Signal Visualization: An important step in biomedical signal processing is the visualization of acquired signals. Data visualization may avoid the unnecessary use of complex tools by evaluating the consistency of the obtained signals and the presence of linear or non-linear trends. At this stage, the visualization tools present in TREMSEN were used. 
- Resampling: the collected data was resampled at a $1 \mathrm{kHz}$ sampling frequency. This step allowed the change of the signals sampling rate.

- Involuntary activity estimate: Involuntary activity was estimated by removing the movements from the collected data. To estimate all the different forms of voluntary movement, a low-pass third-order Butterworth filter with a $1 \mathrm{~Hz}$ limit was used.

- Removal of linear trends: Inertial sensors introduce trends into the data. These trends can originate from the Gravity measurement, the Earth's magnetic field, small movements of another part of the body other than the hand, not related to the movement under study.

- Signal Windowing: Involuntary activity was windowed using $1 \mathrm{~s}$ overlapped windows, so that data could be extracted from each window.

\subsection{Extracted features}

The characteristic that was estimated from involuntary activity was the Mean Absolute Value (MAV), a characteristic that captures changes in signal amplitude.

MAV is defined as:

$$
M A V=\frac{1}{N} \sum_{i=1}^{N}\left|x_{i}\right|,
$$

where $N$ is the number of signal samples and $x_{i}$ is the $i$ - th data sample.

In this paper, Bootstrap was used to estimate the statistical median (Md) of each variable, considering the accelerometer ( $\mathrm{Z}$ axis) placed in the hand and the experimental scenarios. The number of Bootstrap samples was set at 1,000 for the median estimate.

This approach was defined taking into account the findings in a previous paper by the developer group (de Oliveira Andrade et al., 2020), who observed that the $\mathrm{Z}$ axis data analysis of the electrode on the back of the hand was the one with the best clinical representation for tremor, and that the data obtained in the other axes did not include relevant additional information.

A normality test was performed using the Shapiro-Wilk test to assess whether the sample follows a Gaussian distribution. Once the data normality was not verified, non-parametric tests were applied to verify if there was a statistically significant difference among the scenarios.

The Kruskal-Wallis test was applied to assess the medians influence of the MAV value in the intervention scenarios, given by the combination of operating periods and medication status.

When evidenced the statistically significant difference among the groups by the Kruskal-Wallis test, the Wilcoxon test (Pairwise Wilcoxon Rank Sum Test) was applied at a 5\% significance level, adjusted by the Bonferroni correction, to compair the pairs, since this is not a normal distribution sample.

\subsection{Surgical procedure}

Unilateral posteroventral radiofrequency pallidotomy was performed and assisted by microelectrode register (MER), with the patient under local anesthesia. (A. Lozano et al., 1996) The targets were calculated using an indirect technique based on AC-PC and a direct technique based on the fusion of Stereotomography with Brain Magnetic Resonance. 


\section{Results}

Three patients who had undergone pallidotomy and who met the inclusion criteria for the study were analyzed individually, as shown below.

Table 1 shows the values of bradykinesia, rigidity and tremor obtained in the MDS-UPDRS-III assessment, relative to the upper limbs, in different assessment scenarios. These results are qualitatively compared with the results obtained by means of TREMSEN for each individual.

Table 1: values of bradykinesia, rigidity and tremor in the MDS-UPDRS-III assessment, relative to the upper limbs, in different assessment scenarios.

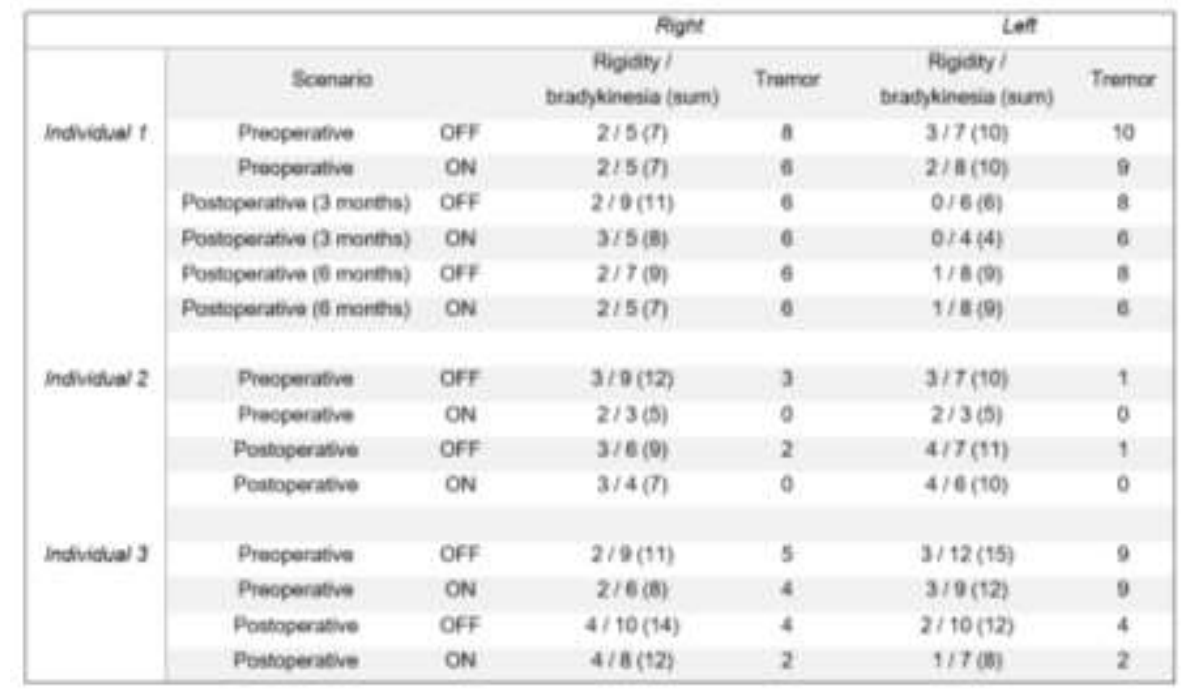

Source: Authors (2021).

\section{Individual 1}

Female patient, 63 years old, diagnosed with Parkinson's Disease, 20 years evolution time, with mixed form of the disease, characterized by the balance among symptoms of bradykinesia, tremor and rigidity, predominant on the left. Her preoperative evaluation showed a score of 26 on the Mini-mental, 22 on the MoCA, Schwad and England of $70 \%$; however, neuropsychological was not an impediment for the procedure, without changes in depression scales and a positive Levodopa test.

The patient underwent pallidotomy on the right, as previous description of the procedure, without intraoperative complications, with good motor response observed by the team in routine consultations. The individual evolved with emotional lability in the postoperative period, being under psychological monitoring, without the impairment of daily activities and very satisfied with the surgery.

In the graph of individual 1 (Figure 8), the involuntary global activity is observed in the following scenarios: preoperative $\mathrm{ON}$ and OFF, postoperative with 3 months ON and OFF and postoperative ON and OFF at 6 months, for both right and left sides. 
Figure 8: Global pattern of individual 1 in each assessment scenario, measured by the Average Absolute Value of Involuntary Activity.

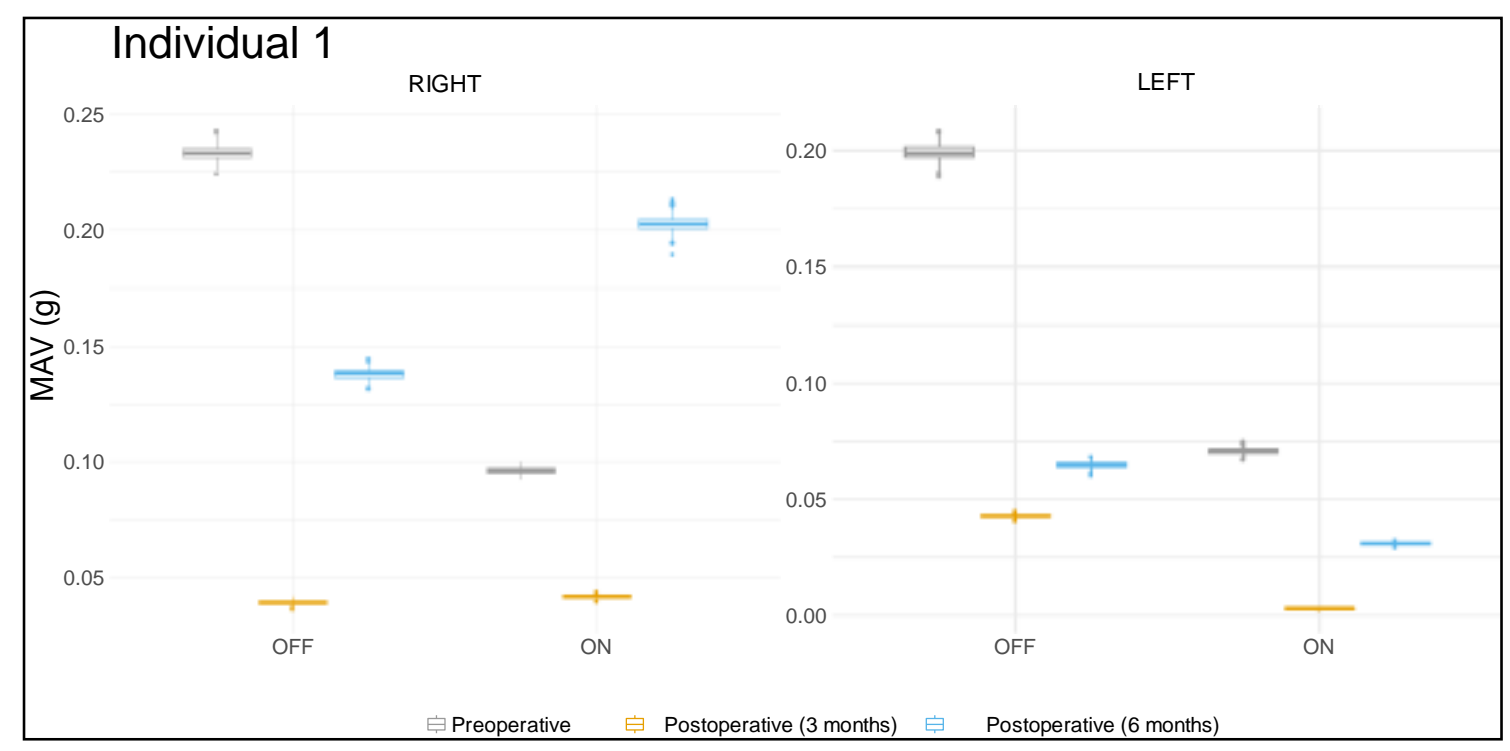

Source: Authors (2021).

On the left side, target of the surgery, preoperatively there was a significant reduction in abnormal involuntary movements in the ON state, compared with the OFF state (Md 0.199 vs 0.07). Regarding the postoperative period, in the ON and OFF states, there was a very pronounced reduction in MAV, both at 3 (Md ON 0.003 vs OFF 0.043) and at 6 months (Md ON 0.031 vs OFF 0.064), although a slightly more pronounced one, at 3 months. However, there was less variation in the MAV between the ON and OFF states in the postoperative period.

In the Kruskal-Wallis test, there was a statistically significant difference among the groups for the limb on the left side $(\mathrm{H}(5)=5832.3$, p-value < 0.05). Paired comparison between groups using the Wilcoxon test confirmed the statistical difference between them ( $\mathrm{p}$-value $<0.05)$.

Comparing these data with the UPDRS-III clinical findings, we noticed that there was a correlation between the reduction in involuntary activity, both in ON and OFF, with a preoperative tremor reduction as well as at 3 months; at 6 months, there was a reduction in the MAV, but no clinical evaluation perception.

On the right side, preoperatively, there was also an important reduction in involuntary activity when comparing the OFF phase with the ON phase (Md 0.233 vs. 0.096). At 3 months, postoperatively, there was no significant difference between the OFF and ON phases (Md 0.040 vs 0.042 ). At 6 months, there was an increase in involuntary activity from the OFF phase to the ON one (Md 0.138 vs 0.202), that is, with the use of medication.

In the Kruskal-Wallis test, there was a statistically significant difference among the groups for the right limb $(\mathrm{H}(5)=$ 5828.4, p-value < 0.05). Paired comparison between groups using the Wilcoxon test confirmed the statistical difference between them (p-value <0.05).

On the right side, which, at first, was not the target of the surgery, there was a tremor improvement in the OFF to the ON phase, corresponding to the MAV reduction. At 6 months, there was no tremor improvement from the OFF to the ON phase. 


\section{Individual 2}

A 56-year-old male patient diagnosed with Parkinson's Disease and having had the disease for 15 years, presented an akinetic-rigid form of the disease, with a bradykinesia and rigidity predominance in relation to the tremor, but also presented this symptom, with a predominance of the disease on the right. The patient's preoperative evaluation showed Mini-mental: 29, MoCA: 25, Schwab and England 25, neuropsychological test and depression tests without changes, good response to levodopa test.

The individual underwent pallidotomy on the left, without intraoperative intercurrences or complications, evolving with a good clinical response observed in routine consultations. In the graph of individual 2 (Figure 9), there is a registry of the involuntary global activity of individual 2 in the following scenarios: preoperative $\mathrm{ON}$ and OFF, postoperative at 3 months ON and OFF, right and left sides.

Figure 9: Global pattern of individual 2 in each assessment scenario, measured by the Average Absolute Value of Involuntary Activity.

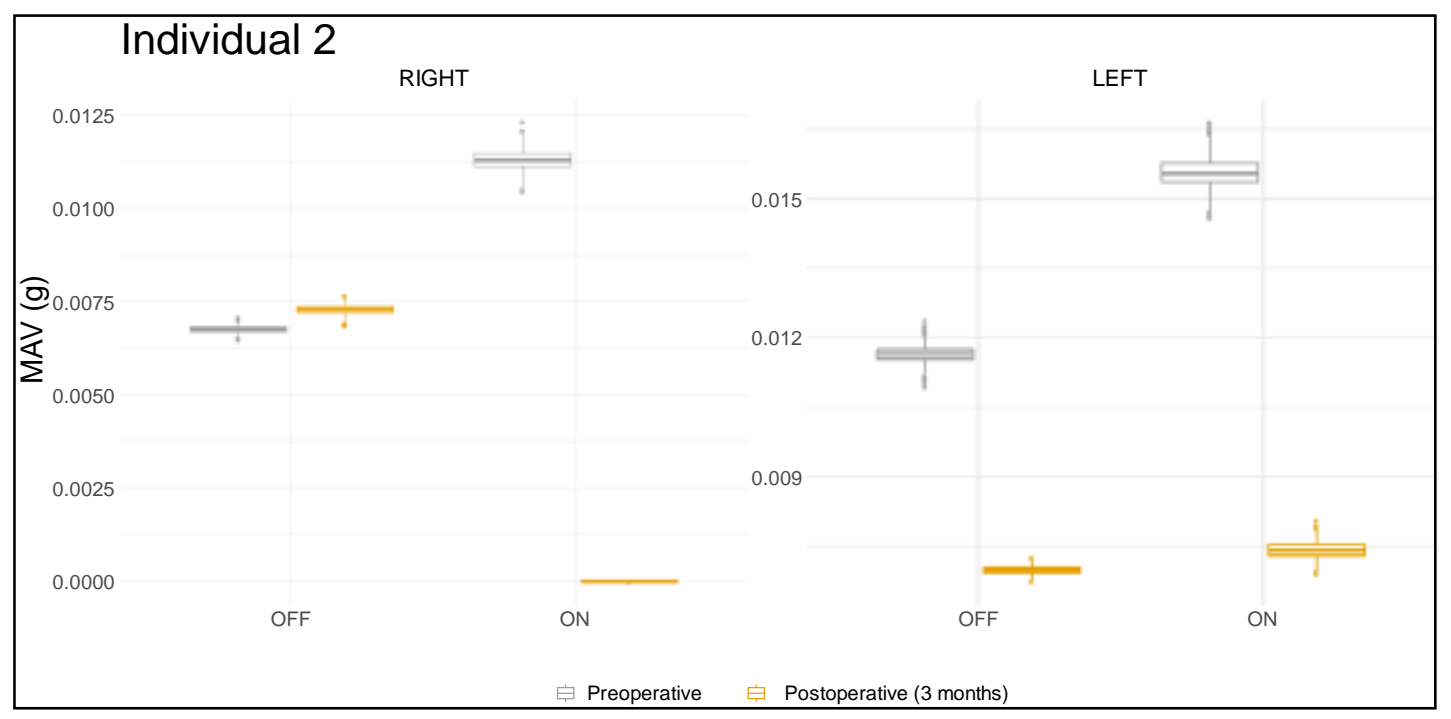

Source: Authors (2021).

On the right side, target of the surgery, there was, preoperatively, a MAV increase in the ON phase, compared with the OFF phase (Md 1.13 x 10-2 vs 6.75 x 10-3). Postoperatively, there was a certain MAV increase in the OFF phase (Md 7.30 x 10-3) yet, a significant reduction in the ON phase (Md 5.81 x 10-3), both when compared to the OFF phase and when compared to the preoperative ON phase.

In the Kruskal-Wallis test, there was a statistically significant difference among groups for the right limb $(\mathrm{H}(3)=$ 3746.4, p-value < 0.05). Paired comparison between groups using the Wilcoxon test confirmed the statistical difference between them (p-value $<0.05)$.

From a clinical point of view, this patient had a mild tremor on this side in the preoperative OFF phase, with a complete response to the medication, as well as a partial improvement in bradykinesia and rigidity, which was related to the MAV increase. Postoperatively, there was a MAV increase in the OFF phase, which was related to a reduction in bradykinesia and rigidity, despite a slight reduction in tremor. In the ON phase, there was an improvement in tremor, rigidity and bradykinesia, which was also accompanied by a MAV reduction. 
On the left side, which was not the surgery target, there was MAV reduction in the postoperative period compared to the pre-operative, both in ON and OFF. There was also a MAV increase from the OFF phase to the ON phase, in the pre (Md OFF 1.16 x 10-2 vs ON 1.55 x 10-2) and postoperative phases (Md OFF 6.98 x 10-3 vs ON 7.41 x 10-3).

In the Kruskal-Wallis test there was a statistically significant difference among the groups for the left side limb $(\mathrm{H}(3)$ $=3738$, p-value $<0.05)$. Paired comparison between groups using the Wilcoxon test confirmed the statistical difference between them (p-value <0.05).

Comparing with the clinical findings, the MAV increase observed between the OFF and ON phases was related to a significant improvement in bradykinesia and rigidity, while the MAV reduction perceived between the pre- and postoperative periods was accompanied by a tremor reduction.

\section{Individual 3}

Male patient, 70 years old, diagnosed with Parkinson's Disease, evolution time of 16 years, presenting a mixed form, with balance among the symptoms of tremor, bradykinesia and rigidity, predominantly on the left. His preoperative evaluation showed a score of 26 on the Mini-Mental, 25 on the MoCA test, Schwab and England of 50\%, with no changes in the neuropsychological assessment or depression tests, good response to the levodopa test.

The patient underwent pallidotomy on the right, without intraoperative intercurrences or complications, evolving well in relation to motor symptoms in the postoperative period, with no worsening of the condition during the usual routine consultations. However, in later consultations, he gradually worsened stability, dysphagia and speech, probably related to the progression of the disease.

The graph of individual 3 (Figure 10) shows the Global Involuntary Activity of individual 3 in the following scenarios: preoperative $\mathrm{ON}$ and OFF and postoperative with 12 months ON and OFF, right and left sides.

Figure 10: Global pattern of individual 3 in each assessment scenario, measured by the Average Absolute Value of Involuntary Activity.

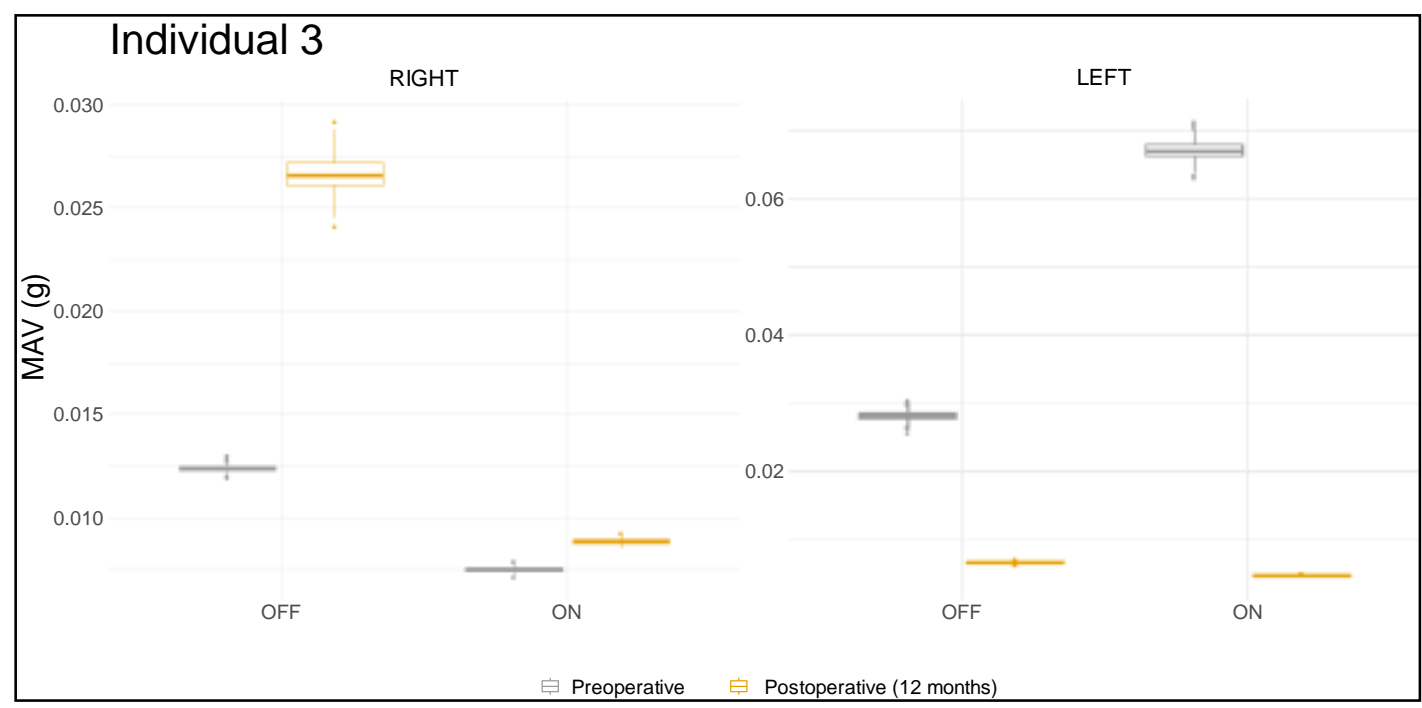

Source: Authors (2021). 
The left side, target of the surgery, showed preoperative MAV increase from the OFF to the ON phase (Md 0.028164133 vs 0.066921777 ). This relation was maintained in the postoperative period (Md OFF 0.006690082 vs ON 0.004789383), however, there was an MAV reduction in relation to the preoperative period.

In the Kruskal-Wallis test, there was a statistically significant difference among the groups for the left side limb (H(3) $=3749.1$, p-value < 0.05). Paired comparison between groups using the Wilcoxon test confirmed the statistical difference between them (p-value <0.05).

Clinically, we noticed that MAV increase from the OFF phase to the ON one in the preoperative period was related to a bradykinesia and rigidity reduction, while the tremor remained unchanged. Postoperatively, there was a tremor reduction in both the OFF and ON phases, when compared with the preoperative period, compatible with a MAV reduction. When analyzing the MAV values in the OFF and ON phases in the postoperative period, we noticed a slight MAV reduction in the ON, accompanied by an improvement in bradykinesia, rigidity and tremor.

On the right side, which initially was not the target of surgery, there was a MAV reduction in the ON phase compared with the OFF phase (Md 0.007495656 vs 0.012391216), and this relation was maintained postoperatively. However, there was a MAV increase in the postoperative period, both in the ON (Md 0.008864021) and OFF phase (Md 0.026583245).

In the Kruskal-Wallis test, there was a statistically significant difference among groups for the right limb $(\mathrm{H}(3)=$ 3749.1, p-value < 0.05). Paired comparison between groups using the Wilcoxon test confirmed the statistical difference between them (p-value < 0.05$)$.

Clinically, on the right side, we observed that pre- and postoperatively there was a tremor reduction between the OFF and ON phases, which was compatible with the MAV reduction in both cases. In the postoperative period, there was a tremor reduction when compared to the preoperative period, which was compatible with the MAV reduction; however, rigidity and bradykinesia worsened.

\section{Discussion}

The role of pallidotomy in Parkinson's Disease management has been reported for decades. Laitinem et al. (1992), in a paper entitled "Ventroposterolateral Pallidotomy can abolish all Parkinsonian symptoms", already highlighted the importance of the technique, reporting the improvement in rigidity and bradykinesia contralateral to surgery in $91 \%$ of patients and contralateral tremor improvement in $80 \%$ of cases $(n=46)$. (Laitinen et al., 1992) Lozano et al. (1998) specifically reported the effect of pallidotomy on tremor in a group of 40 patients, with an 52\% overall tremor reduction, with a contralateral response to the lesion of $67 \%$, sustained after 2 years. (A. M. Lozano et al., 1998)

This effect was also observed in the long run by Hariz and Bergenheim (2001), who reported in a 13 patients cohort, after a 10 years of follow-up, that the pallidotomy effect is quite consistent for contralateral dyskinesias, moderately efficient for tremor, variable for rigidity and dystonia, and discrete for bradykinesia. (Hariz \& Bergenheim, 2001)

When compared with more current techniques, such as bilateral DBS for Subthalamic Nucleus (STN), pallidotomy presents more discreet results. In a randomized study of 34 patients, there was a UPDRS $46 \%$ reduction in OFF in patients undergoing bilateral DBS at the Subthalamic Nucleus, compared with 27\% improvement for unilateral pallidotomy. Nevertheless, there was no statistically significant difference regarding dyskinesia severity, functionality for daily life activities, life quality or equivalent dose of levodopa. (Esselink et al., 2006)

The role of pallidotomy in the DBS era was explored by Spindola et al (2017), who found an average cost of U\$99.5 for each 1\% UPDRS reduction in the OFF phase of pallidotomy, versus U\$873.00 for the same effect in DBS surgery. The author also reinforced advantages in favor of pallidotomy in some specific situations, such as when there is higher surgical risk, higher risk of contamination or difficulty in postoperative follow-up. (Spindola et al., 2017) 
Considering that a significant portion of the surgical result is related to patients' selection, we believe that increasingly objective methods of assessing motor function in Parkinson's Disease can help to select which patients can better respond to available surgical procedures. Since pallidotomy can be more cost-effective and has recognized efficacy and safety, the identification of motor patterns that respond well to this technique presents the possibility of offering a treatment that is equally beneficial to the patient, but less costly for the health system. (Balás et al., 2006; Hua et al., 2003)

The present study aims at evaluating a system capable of accurately quantifying tremor in patients with Parkinson's disease that underwent ablative surgical treatment. The TREMSEN device has already been tested in patients with Parkinson's Disease without surgical treatment, with a good response in the diagnosis functions and patients' follow-up, as reported by Peres et al. (2021) and Andrade et al. (2020). Yet, its applicability in patients that underwent ablative surgical procedure had not yet been tested and, as far as we could see in the consulted data sources, there is still no publication in this regard.

When applied to patients who underwent pallidotomy, we could observe that the Mean Absolute Value of involuntary activity obtained by the TREMSEN method showed a good correlation with the clinical findings, as well as with the findings already described in previous studies. The present study showed that MAV alterations were always positively related to tremor or negatively related to bradykinesia and rigidity, or perhaps both. Also, a tendency towards higher tremor influence on the MAV than bradykinesia and rigidity was observed. In some situations, it was also observed that there was a MAV reduction, with no change in the MDS-UPDRS scale, though.

Probably due to the size of the sample, it was not possible to establish a statistically significant correlation between the values found with the TREMSEN method and the clinical evaluation using the MDS-UPDRS-III; in addition, it was not possible to detect distinct behavior patterns of motor changes among the research subjects. However, there was an important positive correlation, and we believe that with the continuation of the study these doubts can be clarified.

\section{Conclusion}

The present study assessed the applicability of a tremor measurement method based on inertial sensors in patients that underwent surgical treatment at two different times during their treatment: before and after surgery. A good correlation was found with clinical findings, specifically for the Mean Absolute Value of involuntary activity.

We believe that the development of a specific technology can greatly benefit the treatment received by patients, with the optimization of their treatment and more objective and straightforward evaluations.

These technologies have the potential to be used in the future as a method to classify candidates for the surgical procedure according to their motor activity pattern and perform surgical indication with higher precision. Other possibilities include continuous monitoring, remote monitoring or using a feedback loop to adjust stimulation parameters.

For this purpose, in the future, it is necessary to analyze more cases and a longer follow-up. Furthermore, we believe that it is important to correlate the objective evaluation with the surgical prognosis, improving the effectiveness of the preoperative evaluation. Carrying out studies for the development of this technology is essential due to its diverse application possibilities and the impact that Parkinson's Disease represents on the world's population.

\section{References}

Arora, S., Venkataraman, V., Zhan, A., Donohue, S., Biglan, K. M., Dorsey, E. R., \& Little, M. A. (2015). Detecting and monitoring the symptoms of Parkinson's disease using smartphones: A pilot study. Parkinsonism and Related Disorders, 21(6), 650-653. https://doi.org/10.1016/j.parkreldis.2015.02.026

Ascherio, A., \& Schwarzschild, M. A. (2016). The epidemiology of Parkinson's disease: risk factors and prevention. The Lancet Neurology, 15(12), 12571272. https://doi.org/10.1016/S1474-4422(16)30230-7

Balás, I., Llumiguano, C., \& Dóczi, T. P. (2006). Ablative stereotactic surgery improves manual performance time in Parkinson’s disease. Parkinsonism and Related Disorders, 12(4), 223-227. https://doi.org/10.1016/j.parkreldis.2005.11.010 
de Oliveira Andrade, A., Paixão, A. P. S., Cabral, A. M., Rabelo, A. G., Luiz, L. M. D., Dionísio, V. C., Vieira, M. F., Pereira, J. M., Rueda, A., Krishnan, S., \& Pereira, A. A. (2020). Task-Specific Tremor Quantification in a Clinical Setting for Parkinson's Disease. Journal of Medical and Biological Engineering, 40(6), 821-850. https://doi.org/10.1007/s40846-020-00576-x

Defer, G.-L., Widner, H., Marié, R.-M., Rémy, P., Levivier, M., \& Participants, C. (1999). Core Assessment Program for Surgical Interventional Therapies in Parkinson's Disease (CAPSIT-PD). Movement Disorders, 14(4), 572-584. www.bm.lu.se/

Elbaz, A., Carcaillon, L., Kab, S., \& Moisan, F. (2016). Epidemiology of Parkinson's disease. Revue Neurologique, 172(1), 14-26. https://doi.org/10.1016/j.neurol.2015.09.012

Esselink, R. A. J., de Bie, R. M. A., de Haan, R. J., Steur, E. N. H. J., Beute, G. N., Portman, A. T., Schuurman, P. R., Bosch, D. A., \& Speelman, J. D. (2006). Unilateral pallidotomy versus bilateral subthalamic nucleus stimulation in Parkinson's disease: One year follow-up of a randomised observer-blind multi centre trial. Acta Neurochirurgica, 148(12), 1247-1255. https://doi.org/10.1007/s00701-006-0907-1

Gibb, G., \& Lees, A. J. (1988). The relevance of the Lewy body to the pathogenesis of idiopathic Parkinson's disease. Neurosurgery, and Psychiatry, 51, 745752 .

Goetz, C. G., Tilley, B. C., Shaftman, S. R., Stebbins, G. T., Fahn, S., Martinez-Martin, P., Poewe, W., Sampaio, C., Stern, M. B., Dodel, R., Dubois, B., Holloway, R., Jankovic, J., Kulisevsky, J., Lang, A. E., Lees, A., Leurgans, S., LeWitt, P. A., Nyenhuis, D., \& Zweig, R. M. (2008). Movement Disorder Society-Sponsored Revision of the Unified Parkinson's Disease Rating Scale (MDS-UPDRS): Scale presentation and clinimetric testing results. Movement Disorders, 23(15), 2129-2170. https://doi.org/10.1002/mds.22340

Hariz, M. I., \& Bergenheim, A. T. (2001). A 10-year follow-up review of patientes who underwent Leksell's posteroventral pallidotomy for Parkinson disease. J Neurosurg, 94, 552-558.

Hua, Z., Guodong, G., Qinchuan, L., Yaqun, Z., Qinfen, W., \& Xuelian, W. (2003). ANALYSIS OF COMPLICATIONS OF RADIOFREQUENCY PALLIDOTOMY. Neurosurgery, 52, 89-101. https://doi.org/10.1227/01.NEU.0000038933.95427.AE

Laitinen, L. V., Bergenheim, A. T., \& Hariz, M. I. (1992). Ventroposterolateral Pallidotomy Can Abolish All Parkinsonian Symptoms. Stereotact Funct Neurosurg, 58, 14-21.

Lozano, A., Hutchison, W., Kiss, Z., Tasker, R., Davis, K., \& Dostrovsky, J. (1996). Methods for microelectrode-guided posteroventral. J Neurosurg, 84, 194-202.

Lozano, A. M., Lang, A. E., \& Hutchison, W. D. (1998). Pallidotomy for tremor. Movement Disorders, 13(SUPPL. 3), 107-110. https://doi.org/10.1002/mds.870131319

Mera, T. O., Burack, M. A., \& Giuffrida, J. P. (2013). Objective motion sensor assessment highly correlated with scores of global levodopa-induced dyskinesia in Parkinson's disease. Journal of Parkinson's Disease, 3(3), 399-407. https://doi.org/10.3233/JPD-120166

Monje, M. H. G., Foffani, G., Obeso, J., \& Sánchez-Ferro, Á. (2019). New Sensor and Wearable Technologies to Aid in the Diagnosis and Treatment Monitoring of Parkinson's Disease. Annual Review of Biomedical Engineering, 21, 111-143. https://doi.org/10.1146/annurev-bioeng-062117

Postuma, R. B., Berg, D., Stern, M., Poewe, W., Olanow, C. W., Oertel, W., Obeso, J., Marek, K., Litvan, I., Lang, A. E., Halliday, G., Goetz, C. G., Gasser, T., Dubois, B., Chan, P., Bloem, B. R., Adler, C. H., \& Deuschl, G. (2015). MDS clinical diagnostic criteria for Parkinson's disease. Movement Disorders, 30(12), 1591-1601. https://doi.org/10.1002/mds.26424

Ray Dorsey, E., Elbaz, A., Nichols, E., Abd-Allah, F., Abdelalim, A., Adsuar, J. C., Ansha, M. G., Brayne, C., Choi, J. Y. J., Collado-Mateo, D., Dahodwala, N., Do, H. P., Edessa, D., Endres, M., Fereshtehnejad, S. M., Foreman, K. J., Gankpe, F. G., Gupta, R., Hankey, G. J., \& Murray, C. J. L. (2018). Global, regional, and national burden of Parkinson's disease, 1990-2016: a systematic analysis for the Global Burden of Disease Study 2016. The Lancet Neurology, 17(11), 939-953. https://doi.org/10.1016/S1474-4422(18)30295-3

Rigas, G., Tzallas, A. T., Tsipouras, M. G., Bougia, P., Tripoliti, E. E., Baga, D., Fotiadis, D. I., Tsouli, S. G., \& Konitsiotis, S. (2012). Assessment of tremor activity in the parkinsons disease using a set of wearable sensors. IEEE Transactions on Information Technology in Biomedicine, $16(3)$, $478-487$. https://doi.org/10.1109/TITB.2011.2182616

Spindola, B., Leite, M. A., Orsini, M., Fonoff, E., Landeiro, J. A., \& Pessoa, B. L. (2017). Ablative surgery for Parkinson's disease: Is there still a role for pallidotomy in the deep brain stimulation era? Clinical Neurology and Neurosurgery, 158, 33-39. https://doi.org/10.1016/j.clineuro.2017.04.018

Tysnes, O. B., \& Storstein, A. (2017). Epidemiology of Parkinson's disease. Journal of Neural Transmission, 124(8), 901-905. https://doi.org/10.1007/s00702-017-1686-y

Yang, K., Xiong, W. X., Liu, F. T., Sun, Y. M., Luo, S., Ding, Z. T., Wu, J. J., \& Wang, J. (2016). Objective and quantitative assessment of motor function in Parkinson's disease-from the perspective of practical applications. Annals of Translational Medicine, 4(5). https://doi.org/10.21037/atm.2016.03.09 